\title{
Omgaan met verdachten en getuigen in het strafproces; nemo tenetur en cautie
}

\author{
Th.W. van Veen ${ }^{*}$
}

In ons strafprocesrecht wordt omgegaan met mensen. Vanaf het eerste verhoor door de politie tot aan de laatste uitspraak in hoger beroep. Voor de wijze waarop dat behoort te gebeuren zijn regels. Die zijn voor een belangrijk deel opgenomen in het Wetboek van Strafvordering. Bovendien zijn de meest fundamentele uitgangspunten vastgelegd in twee door Nederland aanvaarde verdragen. Dat zijn het Europees Verdrag tot bescherming van de rechten van de mens en de fundamentele vrijheden - in Nederland in werking getreden op 31 augustus 1954 en meestal kortweg het Verdrag van Rome genoemd - en het Verdrag inzake burgerrechten en politieke rechten - in ons land in werking getreden op 11 maart 1979 en in de wandeling het Verdrag van New York geheten. In deze verdragen gaat het vooral om de bescherming van de rechten van de burger tegen willekeurig optreden van staatsorganen. En er wordt een aantal eisen gesteld, waaraan de overheid moet voldoen. Vanaf de Franse revolutie worden in de wetboeken van strafprocesrecht in West-Europa bevoegdheden vastgelegd om inbreuken op de grondrechten te maken, en voorschriften gegeven waaraan bij het maken van die inbreuken moet worden voldaan. Die voorschriften regelen ook aan welke ambtenaren het uitoefenen van die bevoegdheden, gegeven een situatie waarin moet worden opgetreden, is toevertrouwd.

Mocht het Wetboek van Strafvordering een regeling bevatten, die zich niet met de verdragen laat rijmen, dan gaan de verdragen voor. Het Verdrag van Rome, dat in vele opzichten overeenstemt met het Verdrag van New York, althans inhoudelijk, oefent door de rechtspraak van het Europese Hof voor de Mensenrechten direct invloed uit op ons strafprocesrecht. Sommige regels van ongeschreven procesrecht, zoals het beginsel, dat een proces 'fair' moet worden gevoerd, zijn door opname in de verdragen voor ons geschreven recht geworden.

De procesregels opgenomen in wetten en verdragen geven wel een juridisch raam voor het omgaan met mensen, maar zij laten de wijze waarop dat dient te

* Emeritus hoogleraar straf- en strafprocesrecht RU Groningen. 
gebeuren over aan de bevoegde ambtenaren en rechters. Tussen 1930 en 1947 legde de Groningse hoogleraar in het strafrecht M.P. Vrij er de nadruk op dat de verdachte niet behandeld maar bejegend diende te worden, een woord dat, naar $\mathrm{ik}$ heb vernomen, al weer flink versleten is. Vrij bedoelde de aandacht te vestigen op twee aspecten. De verdachte is geen patiënt in de handen van artsen, die het beste met hem voorhebben. Vervolgen en straffen geschiedt omdat de samenleving daar niet buiten kan. Ter handhaving van de wet, en niet omdat deze reactie de aangewezen therapie voor de verdachte zou zijn. Maar ook, de verdachte maakt deel uit van de samenleving, waarin de wet moet worden gehandhaafd. En dat moet men blijven beseffen bij alle afstand, die opsporen, vervolgen en berechten schept. Juist in een door de afstand, die het 'met gezag bekleed' zijn schept, beheerste situatie, dient de waardigheid van de mens, die met het aan hem verlenen van fundamentele rechten wordt onderstreept, niet uit het oog verloren te worden. Daarom zocht Vrij naar een woord als 'bejegening' dat distantie en verbondenheid beide in zich sluit. Het gaat dan óók om procesrechtelijk niet van belang zijnde vragen als: Spreekt men de verdachte met 'verdachte' of met 'meneer zo en zo' aan? Moet 'terecht staan' letterlijk worden opgevat of mag het ook zitten wezen. Wat vraagt men in het openbaar wel, wat niet aan een verdachte omtrent zijn persoonlijke situatie.

Dichter bij het procesrecht zelf staan vragen als hoe men omgaat met de rechten, die de verdachte heeft, en de plichten, die aan de getuige zijn opgelegd. Bij vrijheidsbeneming moeten aanstonds aan een verdachte de redenen van zijn detentie worden meegedeeld (Verdrag van Rome, art. 5 lid 2). Hij, de verdachte, heeft recht op een fair en openbaar proces, op verdediging, op rechtsbijstand, op ondervraging van getuigen (Verdrag van Rome, art. 6). Beide verdragen verbieden marteling (Rome, art. 3, New York, art. 7). Dat verbod omvat inhumaan en mensonterend behandelen. De verdachte mag niet worden gedwongen 'to testify against himself or to confess guild' (New York, art. 14 lid 3,9). Zowel het Verdrag van Rome (art. 6 lid 2) als dat van New York (art. 14 lid 2) kent het voorschrift dat iemand voor onschuldig moet worden gehouden zolang hij niet door een rechter schuldig is verklaard.

Ons Wetboek van Strafvordering is veel ouder dan de beide verdragen. Toen ons land tot de Verdragen van Rome en, later, New York toetrad deden wij die stap in de overtuiging dat ons Wetboek niet veranderd behoefde te worden. Dat gold zelfs voor de onschuldveronderstelling, terwijl in art. $27 \mathrm{~Sv}$ staat dat er een redelijk vermoeden van schuld moet bestaan, willen wij iemand als verdachte mogen aanmerken.

Aan een uitdrukkelijk martelverbod hadden wij weinig behoefte, daar de pijnbank al in de Franse tijd was afgeschaft. Wat ons Wetboek van 
Strafvordering wèl kent is een bepaling omtrent de wijze van verhoren. Art. 29 Sv zegt: In alle gevallen, waarin iemand als verdachte wordt gehoord, onthoudt de verhorende rechter of ambtenaar zich van alles wat de strekking heeft een verklaring te verkrijgen waarvan niet gezegd kan worden dat zij in vrijheid is afgelegd. De verdachte is niet tot antwoorden verplicht. In een tweede lid wordt daaraan toegevoegd: Vóór het verhoor wordt aan de verdachte meegedeeld dat hij niet verplicht is tot antwoorden.

In deze bepaling wordt elke dwang, die zo zwaar is dat van een in vrijheid afgelegde verklaring geen sprake meer is, afgewezen. De formule is ingenieus, maar soms moeilijk te hanteren.

Om een nog al eens voorkomend misverstand uit de weg te ruimen: Er staat niet dat de verdachte niet gedwongen mag worden mee te werken aan het verzamelen van bewijsmateriaal in zijn zaak. Het gaat in art. $29 \mathrm{~Sv}$ uitsluitend over het verhoren van de verdachte. In art. 14 van het Verdrag van New York staat: 'Not to be compelled to testify against himself'. Met 'testify' is het afleggen van verklaringen bedoeld. Dat heeft de Hoge Raad ook meer dan eens uitgesproken ${ }^{1}$. De verdachte kan, als de wet dat toelaat worden gedwongen zich aan lichaam en kleding te laten onderzoeken, bloed of adem af te staan en zich te laten fotograferen.

Deze inbreuken op de grondrechten zijn niet te vergelijken met de marteling op de pijnbank. De pijnbank is niet afgeschaft omdat pijnigen weinig uithaalde. Er is een aantal zaken mee opgehelderd. Er werden ook onjuiste verklaringen afgelegd om aan de pijniging een eind te maken. Met name in heksenprocessen en processen van de inquisitie, waarbij het de ondervragers te doen was om netwerken op te rollen. De afschaffing van de pijnbank vond plaats omdat men het middel mensonwaardig vond en omdat het was en werd misbruikt. Het martelverbod dat wij nu kennen beschermt zowel verdachten als getuigen. Onlangs heeft de Hoge Raad nog uitgesproken dat de rechter een klacht over het in Portugal mishandelen van een getuige in een hier behandelde strafzaak, niet onbesproken mag laten Hij kan niet 'daarlaten' of er wel of niet mishandeld is ${ }^{2}$. Datzelfde zal ongetwijfeld gelden indien er geklaagd wordt over een onmenselijke of vernederende behandeling, bijvoorbeeld gedurende een preventieve hechtenis. Dat kan bij de rechtmatigheid van het verhoor ter sprake komen, wanneer de situatie tijdens een detentie zo is geweest dat een onaanvaardbare dwang tot het afleggen van een verklaring is uitgeoefend.

1. Bijvoorbeeld HR 15 febr. 1977, NJ 1977, 559.

2. Zie HR 1 okt. 1996, NJ 1997, 90. 
$\mathrm{Nu}$ weer terug naar de tekst van art. $29 \mathrm{~Sv}$. De kern van de bepaling is al te vinden in het voorontwerp van het WvSv van 1910 - toen nog zonder de toevoeging dat aan de verdachte ook moest worden meegedeeld dat hij mocht zwijgen. Die toevoeging is per amendement bij de invoering van het Wetboek in 1925 opgenomen. Maar zij gold alleen voor verhoren tijdens het voorbereidend onderzoek. Niet op de zitting. Want ter zitting worden aan de verdachte ook vragen gesteld over zijn persoonlijke omstandigheden. Bijvoorbeeld om na te gaan of een straf voorwaardelijk zou kunnen worden opgelegd. En het zou de verdachte kunnen schaden als hij dan zou blijven zwijgen. Erg overtuigend lijkt dat niet, want de verdachte behoeft op geen één vraag te antwoorden als hij dat niet wil. In 1937 wordt de verplichting om de verdachte op zijn zwijgrecht te wijzen geschrapt. Men vond dat de verdachte als lid van de samenleving of gemeenschap behoorde te spreken. Maar dwingen tot spreken vond men niet aanvaardbaar. De wijziging van de wet vloeide voort uit de roep om een strenger strafrecht. ${ }^{3}$

In 1973 keert, bij een herziening van de regeling van de voorlopige hechtenis, de verplichting tot aanzegging van het zwijgrecht weer in het Wetboek terug. $\mathrm{Nu}$ zowel vóór als óp de zitting. In het derde lid van art. $29 \mathrm{~Sv}$ staat bovendien dat in het proces-verbaal van het verhoor of van de zitting, waarop het verhoor plaats heeft gevonden, moet worden opgenomen of de mededeling van het zwijgrecht is gedaan. Dat zal tenminste zijn bedoeld. Er staat in de wet dat in het proces-verbaal moet worden vermeld dat de mededeling is gedaan. De praktijk heeft zich wel weten te redden. De imprimés, die voor het opnemen van de verhoren worden gebruikt, bevatten de voorgedrukte passage, dat de mededeling is gedaan en de verdachte dus op zijn zwijgrecht is gewezen. Die passage wordt nooit doorgehaald. Wordt het papier met de voorgedrukte zinsnede niet gebruikt dan wordt wel eens vergeten mee te delen dat de verdachte is gewaarschuwd. Al zal het meestal wel zijn gebeurd, uit routine. Daarmee is de beoogde controle door de vastlegging in het proces-verbaal een wassen neus geworden.

Ten onrechte wordt onder Engelse invloed dikwijls van de cautie gesproken wanneer deze mededeling van het zwijgrecht wordt bedoeld. Van een waarschuwing in de ware zin van het woord is geen sprake. De wetgever heeft bewust niet voor het Engelse stelsel gekozen, waarbij de verdachte wordt gewezen op de gevolgen, die zijn zwijgen kan hebben. In de praktijk wordt ook meestal

3. Zie A.L. Melai: Het Wetboek van Strafvordering, commentaar op art. 29, onder 5, de wetsgeschiedenis. Verder G.J.MCorstens: Het Nederlandse strafprocesrecht, hoofdstuk XI, 4. 
volstaan met de mededeling dat antwoorden op de gestelde vragen niet verplicht is.

Zoals gezegd bevat art. $29 \mathrm{~Sv}$ twee elementen. De verhorende rechter of ambtenaar dient zich te onthouden van vragen die antwoorden ten gevolge hebben, die niet vrijwillig zijn gegeven. En hij dient de verdachte op zijn zwijgrecht te wijzen, waarvan in het proces-verbaal melding gemaakt dient te worden.

Wat de eerste verplichting betreft: De verhoor-situatie schept zelf dikwijls onvermijdelijk een aanzienlijke dwang. Alleen reeds doordat uitgegaan wordt van de betrokkenheid bij het plegen van een strafbaar feit door de verdachte. Maar ook door confrontaties, soms met slachtoffers, met foto's van het gebeurde, met voorwerpen, met verklaringen en beschuldigingen van anderen. Ook kan van het verblijf in detentie een zware druk uitgaan.

De woorden 'in vrijheid afgelegd' betekenen dus eigenlijk 'niet onder onbehoorlijke dwang' ${ }^{\prime 4}$. En dan rijst de vraag wat onbehoorlijk is. Daarbij mag niet uit het oog worden verloren dat er niet zelden heel wat op het spel staat bij het ophelderen van een misdrijf. Men denke bijvoorbeeld aan de slachtoffers van het gepleegde feit. Meestal is het voor een rechter nauwelijks uit te maken of klachten over het uitoefenen van een onbehoorlijk zware druk gegrond zijn. Dan staat het woord van de verdachte tegenover dat van de verbalisanten. Die de verklaring op ambtseed (of belofte) hebben opgemaakt.

De sanctie op het onder onbehoorlijke druk ondervragen van een verdachte is tegenwoordig dat de aldus verkregen verklaring niet voor het bewijs kan worden gebruikt. Heeft de dwang zulke vormen aan genomen dat er sprake is van een onmenselijke behandeling van de verdachte door de verhorende ambtenaren, dan kan het niet-ontvankelijk verklaren van het openbaar ministerie op zijn plaats zijn. Maar dat zijn gevallen, waarin de voorschriften opzettelijk zijn geschonden dan wel waar de belangen van de verdachte op grove wijzen zijn veronachtzaamd. $^{5}$

Wij kennen in ons Wetboek geen sancties tegen de verhorende ambtenaar, die onaanvaardbare dwang bij een verhoor heeft uitgeoefend. Dat zou geen onredelijke reactie zijn. Vooral in strafprocessen, waarin aan de waarheid, van de onder dwang afgelegde verklaring, niet wordt getwijfeld en waarin deze verklaring voor het bewijs onmisbaar is, doet het vreemd aan om verklaringen wegens de wijze van verkrijging opzij te moeten leggen, maar degenen, die

4. Een voorbeeld geeft Corstens, t.a.p. p. 253 van een verdachte, die elke dag uit zijn cel werd gehaald voor verhoor, terwijl hij had verklaard niet te willen spreken, HR 23 nov, 1990, NJ $1991,184$.

5. Zie HR 24 sept. 1996, NJ 1996, 725. 
aansprakelijk zijn, te handhaven in hun functie. In een strafproces gaat het immers om de feitelijke gang van zaken, om wat is gebleken.

Controle op de gang van zaken bij verhoren zou verstrekt kunnen worden door het op de band vastleggen van het verhoor.

Natuurlijk heeft ook het toekennen van het zwijgrecht zijn prijs. Er zijn situaties denkbaar, en zij hebben zich ook wel voorgedaan, waarin slachtoffers van een gijzeling niet meer konden worden gered omdat door het zwijgen van een verdachte hun verblijfplaats niet gevonden kon worden. Daaraan is niet te ontkomen.

De Engelsen kennen - tot op zekere hoogte - de cautie wel. Zij waarschuwen de verdachte dat zijn zwijgen in zijn nadeel kan werken. Want wie onschuldig is pleegt te spreken opdat zijn onschuld blijkt. Het Europese Hof heeft daarvoor begrip. Wat de Engelsen doen getuigt van 'common sense'. ${ }^{6}$ Wij zouden ook in die richting moeten gaan. Het is niet erg fair de verdachte te wijzen op zijn recht om niet op vragen te antwoorden, maar te zwijgen over de gevolgen, die het niet antwoorden voor hem zou kunnen hebben. Het is uiteraard niet zo dat het zwijgen van de verdachte een bewijsmiddel is. Maar wel is het zo, dat bij voldoende bewijsmateriaal het zwijgen van de verdachte de rechter kan overtuigen dat de verdachte ook de dader is. En dat dient de verdachte te weten. $\mathrm{Er}$ is meer. Het staat de verdachte rechtens wel vrij te zwijgen, maar moreel meestal niet. In het algemeen dient men de verantwoordelijkheid voor zijn daden op zich te nemen. En een dader, die zijn falen onder ogen ziet en de schuld op zich neemt, zet daarmee de eerste stap naar rehabilitatie of resocialisatie. Niet voor niets is daadwerkelijk berouw in sommige landen een strafverminderingsgrond. En niet voor niets is het weer goed maken van de aangerichte schade, voor zover mogelijk, een belangrijke voorwaarde voor herstel van door het plegen van het delict verstoorde verhoudingen.

De verdachte doet er dus goed aan wel te antwoorden op de aan hem gestelde vragen. Hij is eigenlijk wel verplicht naar waarheid te antwoorden op de aan hem gestelde vragen. Maar hij mag niet tot spreken worden gedwongen en dat moet hem worden meegedeeld. Daarbij gaat het niet om het uitspreken van een in de wet neergelegde formule. Een fair proces vraagt dat de verdachte door de rechter op de hoogte wordt gebracht van de mogelijke gevolgen van zwijgen en spreken. En hoe dat wordt gedaan zal van verdachte tot verdachte - en van rechter tot rechter - verschillen.

6. EVRM, 8 febr. 1996, NJ 1996, 725.

\section{2}


Het verdient nog enige aandacht dat er situaties zijn waarin iemand eerst als getuige wordt beschouwd en pas later als verdachte. Bijvoorbeeld bij ongelukken of vechtpartijen. Dan blijkt soms pas uit de door de politie opgenomen verklaringen wie van de gehoorden als verdachte moet worden beschouwd. Pas dan geldt voor verdere verhoren dat mededeling van het zwijgrecht moet worden gedaan. De tot dan opgemaakte processen-verbaal zijn een wettig bewijsmiddel.

Een tweede categorie vormen de personen, die verplicht zijn inlichtingen te geven aan ambtenaren, die belast zijn met de controle op het naleven van allerlei wetten. Blijkt daarbij dat zij zich aan een strafbaar feit hebben schuldig gemaakt dan treedt bij verdere ondervraging in het kader van de opsporing de status van verdachte in. Hier liggen vragen, waarover de wetgever zich onvoldoende het hoofd heeft gebroken.

Er is een eigenaardige discrepantie tussen de positie van de verdachte en die van de getuige. De getuige is wèl tot spreken verplicht, behoudens in enkele gevallen, waarin de wet hem een verschoningsrecht toekent. Hij kan zelfs door de toepassing van gijzeling (art. $221 \mathrm{~Sv}$ ) tot spreken worden gedwongen. En anders dan de verdachte kan hij onder ede - of belofte - worden gehoord en is hij strafbaar wanneer hij meineed pleegt. In een groot aantal gevallen is de getuige door toeval bij een strafzaak betrokken geraakt. Soms als slachtoffer van het strafbaar feit, soms als voorbijganger, soms ook wel als mededader, die in een proces niet als verdachte maar als getuige wordt gehoord. In tijden, waarin er nog nauwelijks politie was en de opsporingstechnieken in de kinderschoenen stonden, moest de rechter het meestal van de getuigen hebben. Vooral bij een ontkennende, niet op heter daad betrapte verdachte.

Daarom heeft men steeds de getuige gezien als iemand, die verplicht is aan het gerecht diensten te bewijzen. Bij enkele ernstige delicten heeft trouwens iedere burger een plicht tot aangifte (art. 135 e.v. Sr). De pijnbank paste niet zo goed in dat perspectief, want de getuige had niets gedaan. Maar wel paste daarbij dwang tot spreken. Vooral ook, nu op getuigen nogal eens druk wordt uitgeoefend door belanghebbenden om te zwijgen of een valse verklaring af te leggen.

Het dwangmiddel is de gijzeling, enigszins te vergelijken met een dwangsom, die eindigt zodra de getuige bereid is te verklaren of zodra zijn verklaring niet langer nodig is. De gijzeling kan ook eindigen doordat het middel disproportioneel wordt.

Wanneer een getuige ernstige bezwaren heeft tegen het afleggen van een verklaring zal de rechter alleen protesteren wanneer die verklaring voor de reconstructie van hetgeen is voorgevallen onmisbaar is. Zo zal de justitie ook voorzichtig zijn als gevreesd moet worden dat de getuige een meineed gaat 
afleggen. Een dergelijke verklaring is niet bruikbaar. Gebeurt dat toch dan wordt zelden tot vervolging overgegaan omdat wij er niet van houden met de ene rechtszaak de andere uit te lokken. Contempt of court kennen wij ook niet. Voorzover mij bekend wordt in een zaak, waarin achteraf blijkt dat de verklaring van de getuige niet onontbeerlijk was voor de bewijslevering, meineed zelden of nooit vervolgd. Daarmee wordt erkend dat de getuige door toeval en de justitie samen in zijn moeilijke situatie werd gebracht.

Ook de wetgever heeft meer oog gekregen voor de precaire positie waarin getuigen kunnen komen te verkeren. Zo is er in 1993 een regeling voor de bedreigde getuige in de wet gekomen (art. 226a Sv). De rechter-commissaris kan de getuige horen zonder dat diens identiteit bekend wordt. De zittingsrechter kan een verhoor van een bedreigde getuigen aan de rechter-commissaris opdragen. Dat kan hij ook doen bij andere getuigen, bijvoorbeeld slachtoffers van zedendelicten. En dat past weer in de toenemende aandacht voor het slachtoffer in ons strafprocesrecht (art. 51a e.v. Sv).

Daar staat tegenover dat er, mee onder invloed van het Europese strafprocesrecht, een toenemende aandrang is getuigen ter zitting te horen. Hoewel het onwaarschijnlijk is dat een daar afgelegde verklaring betrouwbaarder is dan een eerder bij de politie afgelegde verklaring. Immers, naarmate de tijd verstrijkt vermindert de betrouwbaarheid van verklaringen over wat men heeft gezien of gehoord. Daar komt bij dat de openbaarheid van het strafproces bij belangrijke zaken gaat werken in het nadeel van verdachten en getuigen niet in hun voordeel, zoals was bedoeld. De openbaarheid dient immers om rechter, OM en eventueel raadsman in hun rol te houden, ter bevordering van een faire rechtspleging. Ieder die bij het proces aanwezig is kan en mag vertellen wat hij in de openbare zitting heeft waargenomen. Trouwens: verdachten en getuigen mogen altijd vertellen wat zij, waar dan ook, bij de justitie hebben meegemaakt, een grondrecht van grote waarde. Al wordt dat pas beseft als het verloren is gegaan.

Maar die openbaarheid van het terechtstaan verandert in een extra leedtoevoeging aan verdachten en getuigen wanneer radio en televisie directe uitzendingen uit de rechtszaal gaan verzorgen. Dat kan onder omstandigheden het op een andere wijze herinvoeren van de schandpaal betekenen. En onvermijdelijk gaan rechter, OM en raadsman inspelen op al die luisteraars en kijkers. Dat is niet goed voor de sfeer in de zaal.

Daarmee wordt door mij niet uit het oog verloren dan de rechtspraak het middel bij uitstek is om een volk bekend te maken met enige van de belangrijkste wetten. En dat kan moeilijk zonder openbaarheid. Maar daaraan mogen de belangen van de verdachte en de getuige niet gedachteloos worden opgeofferd. 
Tenslotte is het merkwaardig hoe in veel belangrijke zaken het accent is gaan liggen op de behandeling. De uitspraak, veertien dagen daarna, is een formaliteit geworden, waarbij de verdachte zelden aanwezig is. Hem wordt ook dikwijls gezegd dat hij daarvoor niet terug behoeft te komen. De uitspraak geschiedt ook meestal door een anders samengestelde kamer dan de kamer die de zaak behandelde. Daarvoor zijn allerlei organisatorische redenen. Maar goed is het niet. Het lijkt mij van wezenlijk belang dat de rechter, die de zaak behandelt bij de uitspraak contact heeft met de verdachte. Er valt soms iets te benadrukken, soms iets toe te lichten, soms iets te beantwoorden. Dat zal tact en voorzichtigheid vragen; een eventuele toelichting moet binnen de motivering in het vonnis blijven. Maar het behoort wel bij een behoorlijke bejegening van mensen in het strafproces. 